\title{
The Influence of Frequency on the Acquisition and Textbooks Design of Second Language Vocabulary
}

\author{
Anwar Saad Aljadani \\ Dept. of the General Courses at the Art and Humanities Faculty \\ King Abdulaziz University, Jeddah, KSA \\ Tel: 699-012-695-2000Ｅ-mail: asaljedaani@kau.edu.sa
}

Received: April 11, 2020

Accepted: April 27, 2020

Published: May 5, 2020

doi:10.5296/ijl.v12i3.16831

URL: https://doi.org/10.5296/ijl.v12i3.16831

\begin{abstract}
This paper provides an overview of the role of vocabulary frequency in second language (L2) acquisition as vocabulary is a dominant feature of language acquisition and vitally important to language learners. It reported the vocabulary frequency's significant role in both the earlier acquisition and the easier remembering comparing to infrequent vocabulary in L2 acquisition. It also seeks to discuss the influence of frequency on the selection of vocabulary in L2 textbooks as they are sometime the only source of L2 vocabulary in the classroom. It presents discussions of what vocabulary should be selected, how selective vocabulary are organised in the textbooks to reach determined teaching objectives as well as the teaching rate pre lesson.
\end{abstract}

Keywords: Vocabulary frequency, Second language acquisition, Vocabulary acquisition, Textbooks design and teaching rate

\section{Introduction}

Vocabulary is a dominant feature of language acquisition and vitally important to language learners (Zimmerman, 1997). Knowledge of vocabulary is regarded as the most vital element in language proficiency owing to its association with text comprehension; without knowledge of vocabulary, understand and comprehension of sentences and contexts could be impossible. However, little is known about what causes words to be acquired (Vermeer, 2001). Frequency of occurrence is becoming increasingly difficult to ignore as it is a very important element that plays a crucial function in the acquisition of second language (L2) vocabulary.

It is frequency that is the focus of this paper. The importance of word frequency in language learning has been widely researched. Nagy \& Herman (1987:25), for example, stated that 
"even a single encounter with a word in context" could help to move it "a little bit on the scale of knowledge". Godev (2009) also discussed whether or not the vocabulary used in educational materials is informed by the knowledge of high frequency vocabulary. He argued that, for many language learners, the goal is to communicate in real-life situations; high frequency items are likely to be used in everyday contexts and therefore learning them helps L2 learners to achieve their communicative needs. In light of this, he suggested that "textbooks' lexis should draw on the vocabulary that language users handle most frequently" (Godev, 2009: 52).

This paper is organised in the following way. Firstly, a definition for frequency of occurrence is provided. This is followed by a detailed discussion of the role that vocabulary frequency has in language learning and how word frequency affects the selection of vocabulary in second language textbooks.

\section{Definition of Frequency}

Frequent words are those that are highly likely to be encountered in discourse. As learners are repeatedly exposed to them, it is feasible to say that learners will acquire more frequent vocabulary before less frequent words (Read, 1988). Milton (2009: 23) stated that the most frequent vocabulary tend to be 'function or structure words'. These have little semantic meaning but are, however, "crucial to making grammatical and meaningful language".

Frequency is an important element for vocabulary research. Its classification covers a broad range; The English frequency extends from the most frequent word, the, which takes place 61,847 times per million words, to pernickety, which might be met in discourse only once in many millions of words (Leech et al., 2001). The most widespread classification is highversus low- frequent vocabulary. The high frequent vocabulary is the most fundamental lexis in a language and is compulsory for almost any communicative purpose. There is no constant limitation to this category but some researchers, such as Schmitt et al. (2010) suggested that the first 2,000 lexis (from GSL) are considered high frequency vocabulary.

It is worth mentioning that in the 2,000 words of the frequency list there are certain words that have higher frequencies than others. The first 1,000 vocabulary cover approximately three quarters and the next 1,000 cover approximately 5\% of running words in academic texts (Nation, 2001).

Low frequent lexis has been defined in numerous ways. Some researchers defined it as all lexis beyond the 2,000 academic words level, particularly in studies based on Pull Nation's vocabulary profiler. Other scholars described it as all the words beyond 10,000. This view was built on the Vocabulary Levels Test's highest level and on Hazenberg \& Hulstijns's (1996) finding that around 10,000 vocabulary should be provided for a university study in Dutch (Schmitt, 2010).

Frequent vocabulary levels have been conceived to be an arguable domain. Nagy \& Herman (1987: 20) defined a word family as "a set of words for which there is a predictable relationship in both form and meaning". With regard to Nation's (2006) analysis, a learner needs to know 6,000-7,000 vocabulary families for spoken communication and 
approximately 8,000-9,000 families for a written communication. Consequently, low frequency lexis ought to be considered as all the words beyond the 8,000-9,000 families required for extensive reading in English. However, if a learner acquires sufficient words to read extensively and s/he can also use these words productively then such a person should be successful in most language situations. Moreover, if 6,000 word families or more are needed to speak English it could be hard to say that highly frequent lexis stops at 2,000 families (Schmitt, 2010). Hence, it might be said that there is a need for a category in which the gap between the high frequency words and the amount that is needed for language could be bridged. The mid-frequency vocabulary category (that is the 2,000 to 8,000-9,000 level) is significant, particularly, in terms of pedagogy (Schmitt, 2010). Nation (1990) claimed that there should be a concentration on mid-frequency words. This would assist learners to acquire enough words to enable them to be competent in that language. In other words, this will enable L2 learners to communicate without a shortage of vocabulary.

\section{The Role of Vocabulary Frequency in Vocabulary Learning}

Word frequency has a prominent role in the acquisition of L2 vocabulary. There is a correlation between frequent lexis and likelihood that a learner will face it (Read, 1988). This is a fundamental idea in the measurement of L2 vocabulary acquisition because vocabulary breadth tests are based on this principle. This idea goes back approximately a century to the pre-structuralist scientific method in language teaching (Milton, 2009). Palmer (1917:123) stated that "the most frequent words will be learnt earliest". Thus the frequency hypothesis could be turned into a model which could be tested empirically (Milton, 2009). Aizawa (2006) claimed that a test built on the most frequent bands ought to provide an estimate of vocabulary knowledge which, in turn, allows an examination of vocabulary development throughout the process of language learning.

Another key factor of frequent vocabulary is to assist learners in remembering them perfectly since they leave a memory trace; this effect holds for both formulaic sequences and individual lexis (Tremblay et al., 2008). Frequent words are processed differently and remembered easier than infrequent words and this has been illustrated in a series of ways. For example, Groot (1992) cited in (Schmitt, 2010) showed that more frequent vocabulary could be correctly translated more often, faster and with fewer mistakes than lower frequency words. Indeed Ellis (2002) summarised several researches when he wrote:

"for written language, high-frequency words are named more rapidly than low frequency ones ... they are more rapidly judged to be words in lexical decisions tasks... and they are spelled more accurately... there are strong effects of word frequency on speed and accuracy of lexical recognition processes (speech perception, reading, object naming, and sign perception) and lexical production processes (speaking, typing, writing and signing) in children and adults as well as in L1 and L2" (2002: 152).

Frequency of occurrence is a vital component in L2 vocabulary acquisition and plays a key role in vocabulary utilised in discourse. For example, more frequent vocabulary tend to have less register marking which allows them to occur in a broad number of texts (Schmitt, 2010). 
A very frequent verb such as get, for instance, will link with pronouns ( $I$ get, she gets) and will occur frequently with prepositions to make phrasal verbs (get up, get on) as well as appearing with noun phrases (get married, get dressed).

Another essential function of frequency is that it assists learners to cover a very great amount of the utilised vocabulary in spoken and written texts as well enabling them to understand how these lexical items could be used in a wide variety of ways. As a result, learners will have the ability to improve their reading comprehension and writing proficiency (Nation, 2001). Nation \& Hwang (1995) presented evidence which suggests that learning the 2,000 most frequent lexical items of English is the best decision for learners going on to academic study.

This method seems to be robust at least in terms of characterising populations of learners. An example of this is the study carried out by Milton (2006) in which Greek learners knew about $60 \%$ of the first 1,000 words. This confirms that there is a relationship between frequency bands and vocabulary size scores. This could be viewed as evidence to support the frequency model of learning and the idea that the more frequent a word is, the more likely it is to be learned (Milton, 2009).

It is claimed that learners, as a group, are sensitive to frequent vocabulary which they encounter. Nevertheless, groups are made up of individual learners and it is by no means foreseeable that every learner would be the same in their reaction to frequent words. Consequently, if frequency of occurrence is used as the basis for vocabulary test construction and for the measurement of knowledge, then individual variation could be important. In other words, learner idiosyncrasies must always be acknowledged and, as a result, limitations to generalisations about learners must always be considered. In accordance with a Friedman test on the result of Greek learners acquiring English, in Milton (2006), there is confirmation that individual learners can be affected by frequent vocabulary (Milton, 2009).

Learners will face difficulties when they discover lexical items which are similar in form as this similarity could be confusing for the learner. Nevertheless, such a problem could be overcome by frequency (Milton, 2009); learner difficulties that arise from similarity in form therefore do not refute the importance of frequency.

On the other hand, Gairns \& Redman (1986) and Nation (2001) reported that high frequency is not useful to every learner. Frequency may be a useful guide, as a frequent vocabulary contributes enormously to coverage in general texts, but learnability might be affected by other factors which are not related to frequency such as learners' interests and wants. Milton (2009) mentioned two crucial points with regard to frequency. Firstly, learners tend to acquire words that they associate with their 'needs and interests', even if these words are infrequent. Secondly, frequency does not offer information concerning difficulty. Thus, vocabulary that is frequent may still prove difficult for learners to acquire because of their combination with other words or that, for example, they take irregular inflections. Nevertheless, sufficient repetition may enable the difficulty in acquisition to be overcome. 


\section{How Word Frequency Affects the Selection of Vocabulary in L2 Textbooks}

Textbooks and language input in the classroom also have a role to play in vocabulary acquisition. However, these should not be the only sources of vocabulary input for learners. Exposure to the language in a variety of sources such as films, songs and advertisements should also be used although it is sometimes quite hard to find such sources in certain languages, for example, in French. As a result of this, textbooks and input from the teacher are often the only sources of foreign language vocabulary in the classroom (Milton, 2009).

As already mentioned, textbooks are useful for language learning and the selection of vocabulary to be used in textbooks is equally important. Two main points must be considered. Firstly, what words are selected for teaching and secondly how the material is dispersed throughout the texts. In other words, what vocabulary ought to be in the textbooks and how they should be organised (Milton, 2009).

When course and textbook designers select the vocabulary to be studied, they should pay attention to both frequency lists and learners' needs. Sinclair \& Renouf (1988) illustrated that learners ought to be taught the vocabulary that native speakers use most often, which could be obtained from a frequency list. There appears to be widespread agreement that frequency criteria ought to be fairly prominent in course books. Gains \& Redman (1986), for instance, put frequency at the top of their list of criteria for lexis selection and Palmer (1917) claimed that textbooks and syllabuses should parallel each other in their selection of lexis and other things such as grammar or skills. Choices about vocabulary need to be made carefully because otherwise, learning may be inhibited. However, it has been seen that in the selection of lexical items in foreign language textbooks, the contents have been highly idiosyncratic (Nation, 2001). Milton \& Benn (1933) found in their survey that more than 6,000 types were used and only 19 were common to all the textbooks. Moreover, variety across textbooks prevents measuring progress in a uniform way and makes the selection of content for more advanced learning materials difficult because learners have little in common to build on. Even during the 1920's and 1930's, it can be said that writers were concentrating upon frequency criteria (Nation, 2001). Robson (1934: 265) mentioned that "draws explicit attention to Longman's Modern Method French Book where the contents are derived in this way". Nevertheless, in the present age, the majority of publishers have their own corpora to draw from. It is not always apparent how they chose their content even though frequency criteria could often be identified (Nation, 2001).

Due to the importance of high frequency lexis, as outlined above, considerable time ought to be dedicated to it by both teachers and learners. The vocabulary on frequency lists is small enough that attention to the majority of the list can be achieved over the span of a long language teaching programme. This attention could be in the form of direct teaching, direct learning, incidental learning and planned meetings with the vocabulary. The time spent on them can be "justified by their frequency, cover and range" (Nation, 2001: 16). Overall, it might be recognised that highly frequent vocabulary are extremely important. As a result, Nation (2001) took the view that anything that teachers and learners might do to ensure that they are learned is valuable. 
In terms of low frequency lexis, teachers and learners have a variety of methods that could be used to facilitate acquisition. By way of illustration, teachers could show students how to use strategies to cope with such low frequency words. The strategies involve using word parts to assist in remembering the lexis, guessing from context clues and using vocabulary cards and dictionaries. Low frequency vocabulary lessons enable students to practice these strategies, which could be used later in real-life for other learning needs. For example, the learners' goals may be to maintain or raise their lexical items knowledge. The approaches offer a means of doing so. Once learners learn the high frequency lexis and move on to the study of low frequency vocabulary, the teachers should not spend considerable amounts of class time explaining and giving practice with word knowledge. Nation (2001) thought that teachers should, instead, focus on expanding and purifying the learners' control of vocabulary learning and coping strategies. Learners should also still continue to learn new vocabulary.

Frequency of lexis should also be considered in the organisation of textbooks. Palmer (1917) indicated that as linguists became highly scientific in their study of language learning and teaching, they would have the ability to find an optimal sequence for presentation of this kind of material; in any programme there would be a phase where a lexical item might be introduced to best advantage. Nevertheless, as advantageous as it is to introduce a useful volume of the most frequent words in beginner materials, these materials must also have thematic content. In other words, frequency lists must be appropriately organised by theme or idea in order to achieve coherence. Teachers and textbooks should provide a combination of frequent and structural vocabulary as well as infrequent words. The material should also be balanced with other elements of the syllabus (Milton, 1999).

On the other hand, there is a group of researchers who do not think that it is vital that learners be taught formal vocabulary through the textbooks and classroom language. Harris \& Snow (2004: 55), for example, stated that "few words are retained from those which are ... learned" or "taught" by direct instruction". Moreover, Ellis claimed that "most L2 vocabulary is learned incidentally, much of the time from oral input" (1994: 24).

With regard to teaching rate, researchers have debated how many words should be taught per hour. Gain \& Redman (1986) suggested an average of eight to twelve words as logical input; this equates to 1,000 lexical items being taught in 125 hours of tuition. Schofield (1991), on the other hand, suggested that learners ought to be given an average of nine words per lesson. He also suggested that there should be a cyclic element in the presentation of lexical items, as only certain classes could be expected to focus on this aspect of the language. Other classes, for instance, will need to concentrate on grammar, or skills, or on recycling, reviewing and testing materials that have already been introduced.

\section{Conclusion}

In summary, vocabulary that is frequent, in contrast to vocabulary that is infrequent, is more likely to be learnt and remembered. The importance of frequency has been illustrated in numerous ways. Firstly, it assists learners to memorise and remember them well. Secondly, frequent vocabulary assists learners in understanding a large percentage of lexis that can be utilised in spoken and written texts and how such vocabulary can be utilised in many ways. Thirdly, it can overcome some of the difficulties in L2 vocabulary acquisition such as 
similarity in form and irregular inflections. As discussed above, frequent lexis can influence, and should influence, the selection of vocabulary used in L2 textbooks.

Textbooks and classroom language input play a vital role in vocabulary acquisition but other resources, though they may be difficult to source, are also encouraged. Textbooks should not only focus on the frequency list but also be well organised in order to reach teaching goals. In terms of teaching rate, it is a debatable point as Gain \& Redman (1986) suggested an average of eight to twelve words per hour and Schofield (1991) deemed that learners should be provided with a manageable, short and sweet, average of nine words per lesson. It might be reasonable to some extent to recommend that learners could be taught nine words with their roots and derivations which help learners to use the language flexibly and productively as well.

Finally, it is worth nothing that for effective language learning, hard work is required outside of the classroom; extensive reading and the learning of words that are of particular interest to the student is important as textbooks cannot cover everything and learners have different needs and interests. Moreover, focusing lots of attention on words which are not in frequency lists might be a waste of time.

\section{References}

Aizawa, K. (2006). Rethinking frequency markers for English-Japanese dictionaries. In M. Murata, K. Minamide, Y. Tono, \& S. Ishikawa (Eds.), English Lexicography in Japan (pp. 108-119). Tokyo: Taishkan-shoten.

Ellis, N. C. (2002). Frequency effects in language processing: A review with implications for theories of implicit and explicit language acquisition. Studies in Second Language Acquisition, 24, 143-188. https://doi.org/10.1017/S0272263102002024

Ellis, R. (1994). The study of second language acquisition. Oxford: Oxford University Press.

Gairns, R., \& Redman, S. (1986). Working with words: a guide to teaching and learning vocabulary. Cambridge: Cambridge University Press.

Godev, C. B. (2009). Word-frequency and vocabulary acquisition: an analysis elementary spanish college textbooks in the USA. RLA [online], 47(2), 51-68. https://doi.org/10.4067/S0718-48832009000200004

Harris, V., \& Snow, D. (2004). Class pathfinder: doing it for themselves: focus on learning strategies and vocabulary building. London: CILT.

Leech, G., Rayson, P., \& Wilson, A. (2001). Word frequencies in written and spoken English. Harlow: London.

Milton, H., \& Benn, T. V. (1933). Study of the vocabulary of thirty first- year French course. Modern Language, 14, 11-148.

Milton, J. (2006). X-lex: the Swansea vocabulary levels testing. In C. Coombe, P. Davidson, $\&$ D. Lloyd (Eds.), Proceedings of the 7th and 8th Current Trends in English language testing (CTELT) Conference (Vol. 4, pp. 29-39). UAE: TESOL Arabia.

Milton, J. (2009). Measuring second language vocabulary acquisition. Bristol: Multilingual Matters. https://doi.org/10.21832/9781847692092 
Nagy, W., \& Herman, P. (1987). Breadth and depth vocabulary knowledge: Implication for acquisition and instruction. In M. McKeown, \& M. Curtis (Eds.), The nature of vocabulary acquisition (pp. 19-36). Hillsdale, NJ: Lawrence Erlbaum Associates.

Nation, I. S. P. (1990). Teaching and learning vocabulary. Boston, MA: Heinle and Heinle.

Nation, I. S. P. (2001). Learning vocabulary in another language. Cambridge: Cambridge University Press. https://doi.org/10.1017/CBO9781139524759

Nation, I. S. P. (2006). How large a vocabulary is needed for reading and listening?. The Canadian Modern Language Review, 63(1), 59-82. https://doi.org/10.3138/cmlr.63.1.59

Nation, I. S. P., \& Hwang, K. (1995). Where would general service vocabulary stop and special purposes vocabulary begin?. System, 23(1), 35-41. https://doi.org/10.1016/0346-251X(94)00050-G

Palmer, H. E. (1917). The scientific study and teaching of languages. London: Harrap.

Read, J. (1988). Measuring the vocabulary knowledge of second language learners. RELC Journal, 19, 12-25. https://doi.org/10.1177/003368828801900202

Robson, W. F. (1934). The vocabulary burden in the first year of French. British Journal Educational Psychology, 4, 264-293. https://doi.org/10.1111/j.2044-8279.1934.tb02957.x

Schmitt, N., Candlin, N., \& Hall, D. R. (2010). Researching vocabulary: a vocabulary research manual. London: Palgrave. https://doi.org/10.1057/9780230293977

Schofield, P. (1991). Vocabulary rate in course books - living with an unstable lexical economy. In Proceedings of the 5th Symposium on the Description and/or Comparison of English and Greek (pp. 12-32). Thessaloniki: Aristotle University of Thessaloniki.

Sinclair, J., \& Renouf, A. (1988). A lexical syllabus for language learning. In R. Carter, \& M. McCarthy (Eds.), Vocabulary and language teaching (pp. 140-160). London: Longman.

Tremblay, A., Baayen, H., Derwing, B., \& Libben, G. (2008). Lexical bundles and working memory: An ERP study. Presentation given at the (FLaRN) formulaic language research network Conference. University of Nottingham, June 19-20, 2008.

Vermeer, A. (2001). Breadth and depth of vocabulary in relation to L1/L2 acquisition and frequency of input. Applied Psycholinguistics, 22, 217-234. https://doi.org/10.1017/S0142716401002041

Zimmerman, C. (1997). Do Reading and interactive vocabulary instruction make a difference? An Empirical Study. TESOL Quarterly, 31(1), 121-140.

\section{Copyrights}

Copyright for this article is retained by the author(s), with first publication rights granted to the journal.

This is an open-access article distributed under the terms and conditions of the Creative Commons Attribution license (http://creativecommons.org/licenses/by/4.0/) 